\title{
Cultural responsiveness in the Incredible Years parenting programme for refugees: a case study
}

\author{
Anne Marit Vesteraas Danbolt ${ }^{*}$ (]
}

*Correspondence:

anne.danbolt@inn.no

Inland Norway University

of Applied Sciences, Hamar,

Norway

\begin{abstract}
The Incredible Years is a parenting programme that has been implemented in several countries, and in later years also used in groups consisting of newly arrived immigrant families. The aim of this paper is to explore how refugee parents perceive the cultural responsiveness in the Incredible Years programme offered to a group of newly arrived refugee parents in a municipality in Norway. A key feature of the implementation was the role of the interpreters, as they were considered co-workers with the group leaders and held key roles in the Incredible Years programme. Whilst the dialogic nature of the Incredible Years programme and the open-mindedness of the group leaders promoted a reasonable responsiveness in the implementation, the empowered role of the interpreters was the most crucial point in securing a responsive cross-cultural dialogue. In a situation characterised by uncertainty, the social capital of the family seemed to gain increased value, and the participants were hesitant to discuss any problems with their children. The findings are useful for the provision of the Incredible Years programme to immigrant or refugee families who will need interpreters to take part in the courses.
\end{abstract}

Keywords: Refugee parents, Upbringing, Incredible Years, Cultural responsiveness, Dialogue, Interpreters

\section{Background}

Global mobility and migrating families

Globally, millions of families are on the move and settling under new circumstances. Migration is often self-initiated, but can also be induced by war, conflict or poverty. The last decades have seen a rising number of refugees around the world. The majority of refugees are displaced within their own country or received by neighbouring countries to the areas of conflict, but some refugees settle in the USA, Canada or countries in Western Europe (Migration Data Portal 2017). Family is in itself a driver of migration because family members want to unite across borders, and families thus account for between one-fourth and one-half of the migrant population in the $\mathrm{OECD}^{1}$ countries in 2014 (OECD 2017, p. 108). For the families, such transitions involve crucial differences in social settings and educational systems, as well as in societal norms and regulations of communities. the source, provide a link to the Creative Commons licence, and indicate if changes were made. The images or other third party material in this article are included in the article's Creative Commons licence, unless indicated otherwise in a credit line to the material. If material is not included in the article's Creative Commons licence and your intended use is not permitted by statutory regulation or exceeds the permitted use, you will need to obtain permission directly from the copyright holder. To view a copy of this licence, visit http://creativeco mmons.org/licenses/by/4.0/. 
Many communities and municipalities receiving refugees offer guidance or counselling to support families in the transition phase (see, e.g. Calgary Immigrant Women Association 2019; Skar et al. 2014). Although guidance can take many forms, it always in some way affects the parents' perceptions and beliefs about upbringing. Furthermore, such programmes are usually developed within a western context, more specifically North America or Western Europe, thus voicing beliefs and values from a certain cultural and historical perspective. Any lack of self-awareness or reflexivity of position will have an impact on the implementation of such programmes.

This paper specifically concerns one such parenting programme, the Incredible Years, and has the overall aim of exploring how refugee parents in a particular Norwegian municipality perceive the cultural responsiveness in the Incredible Years programme. Special attention is directed towards aspects of cultural and social capital (Bourdieu 1997), and how identity as parents/caregivers is negotiated through the discourse arising from a manualised parenting programme implemented in a multilingual and multicultural group. The main issue at stake is how to implement a programme developed within a major western culture in such a way that cultural exchanges are ensured rather than cultural imposition (UNESCO 2009, p. 41).

The research questions that guide this research paper are the following: How do newly arrived refugee parents perceive cultural responsiveness in a parenting course based on the Incredible Years programme? How do their experiences in taking part in a multilingual and multicultural group influence identities and values in their parenting practices?

There is limited research on the perceptions amongst culturally and linguistically diverse parents in Norway about Incredible Years programme. This exploratory case study aims at providing more knowledge on how refugee parents, by status in a vulnerable and insecure position, perceive the Incredible Years, a programme they experience through the use of interpreters.

\section{Upbringing, culture and identity}

Upbringing can be described as a "presentation" of a way of life, passing on to the new generation the cultural heritage from the previous generations (Mollenhauer and Friesen 2014). In this view, upbringing is inherently biased, as "we all have been brought up by our parents" (p. 3). The complex task of upbringing incorporates transmissions of values and ideas that are at the core of the relationship between parents and children (Jávo 2010). It takes place primarily within the emotional context of the family, but also within the wider community of the extended family, friends and neighbours, as well as institutions like kindergarten and school. Within this mesosystem (Bronfenbrenner 1986), complex interactions take place in various settings. Thus, upbringing cannot be separated from the culture as a whole (Jávo 2010; Mollenhauer and Friesen 2014), as socialisation takes place within a cultural context. Practices of upbringing are thus not universal: upbringing is embedded in complex social conditions and is sensitive to changes and influences and, as such, also sensitive to migration (Harouna 2018).

The concept of "culture" entails a wide variety of understandings, and is challenging to define (Spencer-Oatey 2012). For the purpose of this paper, a definition of culture that includes the "fuzziness" of the concept is appropriate. In Helen Spencer-Oatey's words, 
Culture is a fuzzy set of basic assumptions and values, orientations to life, beliefs, policies, procedures and behavioural conventions that are shared by a group of people, and that influence (but do not determine) each member's behaviour and his/her interpretations of the 'meaning' of other people's behaviour. (Spencer-Oatey 2008, $p$. 3).

Geertz (1973) advocates a concept of culture that looks at human behaviour as social action (p. 10). He states that cultural analysis must be in touch with the "hard surfaces" of life, even whilst striving for a deep analysis of human behaviour (p. 30). Aspects of meaning, as embedded in everyday chores and activities, are thus central to the understanding of culture.

Bourdieu (1997) looks at culture as a form of capital. In its "objectified state", culture may be associated with material objects and artefacts, like paintings, monuments, literature etc. (Bourdieu 1997, p. 50), which may also be appropriated symbolically as cultural capital. Furthermore, cultural capital can take the form of academic qualifications that can be converted into monetary value, as formal education renders a legally guaranteed value (Bourdieu 1997). The Norwegian anthropologist Fredrik Barth highlights the intangible aspects of culture as ideas, knowledge, conventions, attitudes, norms and values from experiences and learning (Barth 1998). This definition is closely linked to the concept of upbringing as described by Mollenhauer and Friesen (2014). There is thus an obvious relationship between upbringing and culture; however, one must keep in mind that cultures are shifting entities (UNESCO 2009, p. 39), and should not be perceived as monolithic or unchangeable (Spencer-Oatey 2012). On the contrary, cultures are complex and flexible and are negotiated through new encounters and experiences (Cohen and Kassan 2018). It should also be clear that practices of upbringing cannot be associated unambiguously with a certain cultural context.

Experiences in families and social settings as well as membership in one or more communities have an impact on how identity is formed. Migrating parents must construct new and adaptive identities whilst keeping a symbolic continuity (Harouna 2018, p. 41). Cohen and Kassan (2018) explored how emerging adult immigrants in Canada negotiate their cultural identities, navigating between their culture(s) of origin and the Canadian culture where they have settled. They found that motivation and sense of agency is at the core of cultural identity negotiation, and with age, the participants expanded their worldviews which allowed for a more meaningful exploration of cultural identity (Cohen and Kassan 2018, p. 140).

In transitions into new communities, migrating families must adapt to new circumstances that might imply different sets of values, outlook on life and views on upbringing and the relationship between parents and children, which will also have an impact on their identity. Harouna's (2018) research in refugee camps in Cameroon reveals a picture of a new family dynamic, where the process of learning new codes, values and intergenerational transmissions was dependent on the women (p. 39). The fact that migration may disturb the balance within the family is also a finding in a study of immigrant families with children with disabilities (Haines et al. 2017).

Even though migrating parents have demonstrated a great deal of strength as well as the ability to overcome barriers in the process of transition, their qualifications may be 
invisible or ascribed to less value than previously in their new community. They may thus experience a devaluation of their cultural and social capital because less symbolic value is ascribed to them as professionals, language users or as members of the community (Bourdieu 1997). Immigrants often experience marginalisation, or what RodríguezValls and Torres (2014) term "anonymization", implying a loss of identity in the process of transition. Subtle mechanisms of power exertion may form barriers against inclusion, as their previous educational qualifications cannot easily be transferred into economic capital through paid work (Bourdieu 1997). Adding to this situation, their social capital through durable networks is normally considerably reduced, and membership in new groups or communities may be hard to obtain. Such conditions place newly arrived families in vulnerable situations as regards power relations, social status and networks. This devaluation of social and cultural resources also has a bearing on the context of upbringing and life in the families (Jávo 2010). A shift in social conditions also has an impact on identity, as a person's identity will shift in accordance with changing social and economic relations, and migration will be accompanied by a negotiation of cultural identity (Cohen and Kassan 2018).

\section{Cultural responsiveness in cross-cultural interaction}

In this article, the term cultural responsiveness includes the ability to relate to members of other communities, with other backgrounds and experiences, in a respectful way. This implies that communication should be open, friendly, interested and non-condemning. UNESCO points out the challenges of preserving cultural identity and promoting intercultural dialogue (UNESCO 2009, p. 5). Taking part in cross-cultural communication also demands self-awareness to avoid ethnocentricity (Jávo 2010, p. 155). As upbringing is inherently rooted in a cultural context, different views of family life and the relationships between family members may arise. In such cases, a respectful interaction in addressing family practices and relationships between parents/caregivers and children is vital. Imposing certain world views or certain perspectives on upbringing may be felt to be intrusive. However, there are differences in legal regulations that have implications for social life as well as life in the family. One such example is that some countries adhere to regulations prohibiting physical violence against children, whilst other countries are silent on this point (WorldAtlas, n.d.). Another example is the expectation from kindergartens and schools for parents to take an active and supporting part in collaborative activities and engage with their children's homework.

The issue of cross-cultural interaction becomes especially poignant when it comes to treatment. ${ }^{2}$ All approaches are not universally applicable and must be tailored to the people in question. Traditional family structures may in some cases interfere with therapy for children, and one should be aware of the danger of an ethnocentric bias. Jávo et al. (2000) raise the issue of cultural variation in parental norms as such norms may influence how parents interpret their children's behaviour. Cultural norms may prevent

\footnotetext{
2 The families in this case study did not take part in treatment. However, the Incredible Years was originally developed as a treatment programme for families with children with conduct problems (Webster-Stratton 2005), and elements of the treatment programme were integrated in the course delivered to the case group in this study.
} 
parents from sharing sensitive information with people outside of the family, as this is considered inappropriate.

Culturally responsive ways of dialogue must take possible differences in cultural norms into account. However, there are also differences within cultures, which should not be overlooked. Campell (2000) warns against cultural stereotyping, where individual and intra-cultural differences are concealed. People are individuals and their identity cannot be defined solely by nationality, ethnicity and language. In dealing with people of different life experiences and cultural backgrounds, there is a clear need to balance awareness of cultural differences without resorting to prejudices or cultural stereotypes. Assigning same-ethnicity professionals in treatment is one way of contributing to the outcome of treatment. To preserve an authentic responsiveness to individual differences, cultural knowledge must be translated into therapeutic behaviours and decisions, and cultural "matches" in treatment are more likely to achieve positive results.

\section{Recent policies towards refugees in Norway}

Norway is amongst the 145 countries that have recognised the Geneva Convention of 1951, protecting the rights of refugees (European Commission 2018; UNHCR n.d.). Only a very low number of refugees came to Norway during the first decades after the Second World War. The first considerable wave of refugees arrived towards the end of the 1970s, bringing people from Chile and Vietnam, though the numbers were still low in an international perspective. After the stop of work-based immigration in 1975, the 1980s and 1990s brought asylum seekers from countries like Sri Lanka, Iran, Ethiopia, Somalia and countries in the former Yugoslavia, and after the turn of the century Norway received refugees from Iraq and Afghanistan. The most recent influx of refugees has been the considerable number of people fleeing from the war in Syria. Many people who have left Eritrea and other countries in Eastern Africa have also settled in Norway. Still, the percentage of people with a refugee background is low: whilst $14.4 \%$ of the Norwegian population have an immigrant background, only $4.4 \%$ have a refugee background (Statistics Norway 2019).

Refugees may come either as asylum seekers or they may be included as resettlement refugees in the quota agreed upon with the UN Refugee Agency (UNHCR) and being brought directly to Norway from refugee camps abroad (Norwegian Directorate of Immigration n.d.a). Refugees are granted a temporary residence permit for between 1 and 3 years. Family members may also be granted a family immigration permit based on certain criteria. It is not possible to apply for a permanent residence permit before 3 years' residence in the country.

The debate around immigration has been rather heated in many European countries, especially during the situation in 2015 when large numbers of refugees were crossing the borders into Europe. Only a small fraction of the migrant stream reached Norway, but the influx was considerable with more than 30,000 people seeking asylum, more than tripling the number from the previous year (Norwegian Directorate of Immigration n.d.b), and thus creating an urgent pressure on public services (Meissner and Vertovec 2015).

Refugees who are granted a temporary residence permit are settled in designated municipalities, after a request to the municipality by the Norwegian Directorate for Integration and Diversity (IMDI). The municipalities receive economic support from 
the government based on the number of refugees they will settle. The municipalities are obliged to offer an introduction programme for refugees, which must include three elements: Norwegian language classes, courses providing knowledge about the Norwegian society, and educational or work-related activities. Participation in the introduction programme is mandatory and refugees have a right and an obligation to complete the programme (Directorate of Integration and Diversity 2018).

The municipalities have some freedom in deciding the content of the introduction programme within the framework described above. In one semi-rural municipality in Norway, the local administration decided to include a parenting programme as part of the introduction programme for newly arrived refugee parents. As some of their key personnel were well acquainted with the Incredible Years, they chose to adapt this programme to the new setting. The background was amongst others that teachers in schools reported that some children from refugee families tended to become involved in conflicts and their parents seemed to have difficulties in dealing with such situations. The municipality was worried that they had not been providing sufficient assistance to newly arrived immigrants, and therefore applied for funding to introduce a parenting course aiming at a better provision for immigrant parents. The aim was to guide them in their parenting practices and give information about laws, regulations and traditions in Norway.

\section{The Incredible Years programme}

The Incredible Years (IY) is a group-based programme for parents with children aged 3-8 years, developed in the USA by Carolyn Webster-Stratton. Initially created as a treatment programme for families with children with conduct disorder, the scope has expanded considerably and the Incredible Years has developed a series of programmes used for prevention purposes ${ }^{3}$ (Menting et al. 2013; Incredible Years, n.d.a). Amongst key features of the parenting programme is the aim to promote responsive and sensitive parenting, using the principle of positive attention and nonviolent discipline (Webster-Stratton 2005, p. 18). The content is described through the metaphor of a pyramid, where the base consists of approaches that will build a strong attachment between parent and child, thus creating a solid foundation for the child-parent relationship. These approaches are empathy, attention and involvement, play, problem solving, listening and talking, and should be used frequently. The programme furthermore promotes praise, encouragements, rewards and celebrations. Moving upwards in the pyramid the parents learn about clear limits, household rules and consistent follow-through, together with employing the approaches of ignoring, distracting and redirecting. At the top of the pyramid are techniques that should be used selectively: time-out, loss of privilege, and natural and logical consequences (Webster-Stratton 2005, p. 24).

The programme is delivered by trained group leaders who follow manuals throughout the sessions. To introduce a topic, they use tools like short videotapes (vignettes) illustrating a typical situation in the home (or at school) where a parent (or a teacher)

\footnotetext{
3 There are several programmes aiming at prevention of conduct problems in Norwegian schools, e.g. the Parent Management Training-Oregon (PMTO), Early Intervention for Children at Risk (TIBIR), and Positive behaviour, supportive learning environment and interaction (PALS).
} 
and one or more children are interacting. Another tool is role-play where parents are involved and follow directions from the group leaders, practicing strategies that they have observed in the vignettes and discussed. The participants are also given home assignments to practice what they have learnt, and the home assignment for the previous week is often the starting point for discussion in the meetings.

The Incredible Years builds its theoretical framework on several sources, amongst others Piaget's theory of children's cognitive development, theories of children's susceptibility to environmental impact, and compulsive, negative interaction and association and relationship theories (Fyhn 2017). Particularly prominent are Bandura's model learning theories and the theory of self-efficacy. The group-based approach and the cooperative nature are highlighted as important resources in the parenting programme (WebsterStratton 2009).

Disadvantaged socio-economic settings have been associated with higher levels of disruptive behaviour and conduct problems amongst children (Leijten et al. 2017; Mcgrath and Elgar 2015). There is much research on the Incredible Years as treatment for families with children with conduct disorder, showing improved relationships within families, increased levels of positive attention from parents/caregivers, decreased use of harsh discipline techniques and raising levels of parental mood/self-efficacy amongst parents (e.g. Drugli et al. 2007; Furlong and McGilloway 2011; Leijten et al. 2017; Seabra-Santas et al. 2016). Several studies focus on the Incredible Years programme as prevention programmes in schools (e.g. Fossum et al. 2017; Kirkhaug et al. 2013; Reinke et al. 2012; Webster-Stratton and Herman 2009). These studies are mainly published in journals for developmental or clinical psychology.

The Incredible Years is promoted as culturally sensitive, as it is attentive to cultural diversity and is delivered in a collaborative way (Webster-Stratton 2009). Webster-Stratton brings forward five principles that are important when working with multicultural parent groups. Amongst these principles are the following: respecting and affirming cultural differences; exploring, understanding and addressing possible cultural barriers to intervention content; and working collaboratively with interpreters. Webster-Stratton underscores the role of the group leaders to be collaborative in their approach and take time to listen, understand and acknowledge cultural differences (Webster-Stratton 2009, p. 30).

One example of research to support the view that the Incredible Years is effective with diverse groups is a study carried out in the Netherlands describing the effects of the Incredible Years offered to parents of low socio-economic status (SES) and immigrant background. This study finds parents reporting less disruptive child behaviour as well as an increased use of praise and incentives. Furthermore, the study found that the effectiveness did not differ across families with different socioeconomic and ethnic backgrounds (Leijten et al. 2017). Furlong and McGilloway (2011) investigated the effect of the Incredible Years in a group of families with low SES and children with conduct problems in Ireland. This study found that parents experienced problems in using praise and positive attention towards their child, as this was perceived as inconsistent with traditional norms of child rearing. However, the participants reported that the programme had produced positive changes through key parenting skills and through enhanced parental confidence. 
The Incredible Years has also been adapted to newly arrived refugee and immigrant families, using interpreters as crucial mediators. One example is the implementation of the programme as a part of the Children and Parents Services (CAPS) in Manchester (UK), both to parents who speak English as a second language and to parents who do not speak English at all (Central Manchester University Hospitals/NHS 2015). However, research-based knowledge of such adaptations is scarce. One example of a researchbased study was carried out amongst first-generation Korean mothers aimed at testing the effect of the Incredible Years to Korean American mothers in the USA. This study found that the Incredible Years programme proved effective in reaching Korean American mothers because they reported increased use of positive discipline and decreased use of harsh discipline (Kim et al. 2008). One distinctive feature of this research is that the programme was delivered in the Korean language, explicitly addressing the need of immigrant parents to learn about parenting practices and the culture of the country of residence in their first language.

The Incredible Years programme has been implemented in Norway since 1999. More than 130 municipalities (approximately one-third of the total number of municipalities in Norway) have implemented the programme since the turn of the century (Fyhn 2017). The programme has also faced criticism for lacking reflection on democratic perspectives about upbringing when used as a prevention programme offered to kindergartens and schools (Østrem 2016).

Whilst the main bulk of the research on the Incredible Years is conducted within the framework of clinical or educational psychology, this study does not aim at testing the effectiveness of the programme per se. The focus is rather on how special features of the programme are perceived by participants of diverse cultural backgrounds.

\section{Methods}

\section{Design}

The research design was an exploratory qualitative single-case study of a special case (Yin 2014, p. 52). Qualitative research tries to explore and understand "the meaning individuals or groups ascribe to a social or human problem" (Creswell 2014, p. 4) which fits well with the aim of capturing the perceptions of the participants of the programme and trying to understand their worldviews in the context of being newly arrived immigrants. Through thorough data gathering over a period of 10 months, the study was aiming at a deep analysis by interpreting the social discourse that took place in meetings as well as through interviews.

The course based on the Incredible Years programme delivered to the case group took place from August until June the next year. Data were collected through non-participatory observations in 17 of a total of 332 -h meetings, and in addition semi-structured interviews with all parent participants, interpreters and group leaders. The interviews took place immediately before or after the meetings, and the interpreters assisted in interviewing the parent participants. Furthermore, the participants' final written individual evaluations of the programme were analysed. Previous to the data collection in the case group, the researcher was present in a meeting with the previous group of refugee parent participants, and used this meeting as a pilot observation. 
Table 1 Overview of data collection

\begin{tabular}{ll}
\hline Type of data & Size of data sources \\
\hline Field notes from one meeting, piloting observation & 1 2-h meeting \\
Field notes from meetings with case group & 17 2-h sessions \\
Field notes from introductory course for interpreters & 1 2-h session \\
Transcripts from interviews with parents & 7 interviews, 30-70 min \\
Transcripts from interviews with interpreters & 2 1-h interviews \\
Transcripts from interviews with both group leaders & 2 1-h interviews \\
Final written evaluation of the course, including free comments & 9 forms
\end{tabular}

Before the course for the case group started, the researcher observed one session of a 3-day introductory course for the interpreters. The course leaders considered this course essential for a successful implementation, as it provided the interpreters with a deeper insight into the special features of the Incredible Years programme. One of the course leaders had discussed this implementation with the founder, Carolyn Webster-Stratton, to ensure fidelity. The researcher was not familiar with the Incredible Years before the research started, and had no role in the implementation of the course.

The observations in meetings rendered the most extensive part of the data. The researcher made notes on her laptop during the meetings, and as all communication was translated, this allowed for comprehensive field notes. All interviews with parent participants, interpreters and group leaders were audio-recorded and transcribed by the researcher.

Field notes and transcriptions from interviews generated large amounts of data. The written data were analysed by a coding process, where the codes were allowed to emerge and develop during the analysis (Creswell 2014, p. 198-199). Special attention was directed towards situations in the meetings with high emotional intensity. The different sources were useful for the triangulation of data, as well as for shedding light on events that occurred during the sessions (Table 1).

\section{Participants and setting}

A group of ten people, seven females ${ }^{4}$ and three males, took part in the Incredible Years training course during the year of data collection. They represented six different families. There were seven persons, including three couples, of newly arrived refugees from an Arab-speaking country, two females from two different African countries and one single mother from an Asian country. In addition, one husband who had completed the course in the previous year occasionally participated in the classes. Some of the participants had arrived in Norway just 4 months earlier, some had stayed in Norway for a couple of years but had been allowed to postpone both the course and the language classes because of care for new-borns. The participants' educational backgrounds varied from no formal education (one female participant), others had completed between 6 and 12 years of schooling whilst some had professional training. The husbands had

\footnotetext{
${ }^{4}$ One of the female participants finished her introduction programme a few months into the data collection period and did not take part in interviews.
} 
all worked as skilled workers in their home country, whilst the female participants had mostly worked in their homes, as they all had young children. One of the female participants was a trained health professional from her home country.

The parent participants were all assigned to the course as part of their mandatory participation in the introduction programme, and both mothers and fathers were required to do the course. As they were all newly arrived immigrants and Norwegian language learners, each language group had their own translator. The interpreters of the four different languages were two females and two males. The two group leaders were both females and trained as group leaders in the Incredible Years programme.

All communication in the group sessions involved the interpreters. Every utterance from the group leaders was translated into the different languages, and all utterances from the participants were translated into Norwegian and then translated to the other languages. The meetings sounded occasionally like a linguistic cacophony, when four languages were spoken simultaneously in the room, mixed with outbreaks of laughter and engaged voices.

The study took place in a semi-rural municipality in the eastern part of southern Norway. The municipality had received refugees for many years and had established good provisions for the immigrants with respect to pre-school and school placement and support for the children and language courses for adults.

\section{The content of the Incredible Years course offered to the case group}

In this case group, elements from the treatment programme and the prevention programme were combined to tailor the course to this specific group of participants. The topics during the meetings followed manuals developed by the Incredible Years: Attention and involvement in play, coaching, praise, incentives, routines and house rules, clear limits, ignoring, time-out, consequences, problem-solving and self-regulation (WebsterStratton 2005, p. 24). In addition, the course included two meetings about the Norwegian Child Welfare Services (Table 2).

\section{Ethics approval and consent}

Ethics approval was obtained from the Norwegian Centre for Research Data (NSD), including approval of information letters to each of the participant groups and individual consent forms. Information about the project was provided through oral information from the researcher and a written letter in Norwegian, which was interpreted orally into the languages of the participants. This procedure allowed for questions and clarifications. It was made clear that they could withdraw from the study at any time, and participation in the interviews was voluntary. The participants signed the consent form towards the end of the first meeting where the researcher was present.

There are obviously special ethical concerns in conducting a study of this kind. Reflections on power relations and the researcher effect are crucial. Refugees and immigrants might carry with them difficult or even traumatic experiences, and are therefore considered a vulnerable population (Creswell 2014, p. 95). Talking about family life and relations might lead to turbulent feelings and a sense of loss, and research should not add further stress to such a situation. However, the participants clearly appreciated the 
Table 2 Topics covered in the Incredible Years course

\begin{tabular}{ll}
\hline Topics & $\begin{array}{l}\text { Number } \\
\text { of meetings }\end{array}$ \\
\hline Presentation of the children in the families & 1 \\
Child-centred play and attention in play & 3,5 \\
Coaching & 1,5 \\
Norwegian Child Welfare Services ${ }^{\text {a }}$ & 2 \\
Praise & 3 \\
Praise, and talking about visits to the library & 3 \\
Tangible rewards, incentives & 3 \\
Routines and rules in the home & 2 \\
Good commands & 2 \\
Discipline, limit-setting, follow-up on messages & 2 \\
Ignoring & 2 \\
Time-out & 5 \\
Natural and logical consequences & 1 \\
Problem solving and self-regulation & 1 c \\
Closing meeting: summing-up and evaluation & 1 \\
Number of meetings & 33 \\
\hline a Information about the Norwegian Child Welfare Services was added to the course and approved by the Incredible Years \\
founder \\
b The group leaders did not use the equivalent to the word "command"in Norwegian. They chose the word "beskjed", which \\
may be translated as "message" \\
c One of the planned meetings on problem-solving and self-regulation had to be cancelled because not all the interpreters \\
were available
\end{tabular}

opportunity to talk about their family as well as their perceptions of the programme, and no one refused to take part in the interviews. Some also used the interview to talk about concerns related to their children, thus demonstrating their trust in the researcher as well as the interpreter. The researcher's continual presence in meetings during nearly 1 year probably added to this trust.

\section{Limitations}

The issue of reflexivity has been taken into consideration in the analysis of the data. The researcher necessarily influences the data only through his or her sheer presence. In addition, the fact that the researcher shared a similar background as the two group leaders, female middle-class Norwegians, may have contributed to fidelity to the course and also discouraged the participants from rendering any critical viewpoints. Another limitation is the fact that the translators in the course sessions also carried out the translations in the interviews. This could prevent the participants from voicing criticism, as the translators naturally were associated with the Incredible Years course. Although the impression was that the participants voiced their opinions quite freely, also those that were of a more negative kind towards the course, these limitations should be kept in mind. 


\section{Results and discussion}

The data provided a rich and complex picture of the situation of these parents struggling to adapt to a new context. The multiple interactions between participants of different language backgrounds, the interpreters and the group leaders occasionally created situations of tension during the meetings. These situations were considered especially poignant from a research perspective. Yet another feature of the data was the fact that interesting perspectives emerged during the interviews that had not appeared on the surface in the sessions.

The following overarching themes emerged through the analysis of the data:

- The value of dialogue in a multilingual and multicultural group.

- The family as social and cultural capital in a fluctuating context.

- The interpreters as gatekeepers and cultural "brokers".

\section{The value of dialogue in a multilingual and multicultural group}

The overall response to the course from the parent participants was positive, as conveyed through the observations, the interviews and the final evaluations. With one exception, the parents said that they would like to recommend the course to others. They appreciated the opportunity to receive information about the Norwegian society and talk about important issues regarding upbringing. They emphasised the cultural aspect and pointed to the usefulness of the programme when it comes to living as a family in a new country:

We have got new information, we have learnt about a new culture, this course is a resource in learning how to cope in a new society.

Some of the participants explicitly mentioned that taking part in a mixed group gave the course an additional value, thus highlighting the benefits of the diversity of the group.

We have learnt about Norwegian culture, but also learnt from our fellow participants, because there are different cultures, not only the Norwegian one.

From these statements, it is interesting to see that the parents mention the value of information related to living in a new society. In other words, they had learned something as newcomers to the community and not explicitly as parents. However, some participants mentioned in the final evaluation that they had gained more confidence as parents.

Tense situations arose when topics like praise and ignoring were on the agenda. Praise and encouragement are key approaches in the Incredible Years programme, as it is considered that this can help children to master new skills and develop a positive self-image, as well as giving the motivation to stay with a difficult task (Webster-Stratton 2005, p. 41). Several studies have reported that some parents feel unfamiliar with positive attention and praising their children (Kim et al. 2008; Furlong and McGilloway 2011). This was also the case amongst some of these parents. As a response to a vignette emphasising the value of praise, an interpreter commented "This has to do with culture, we think it is the opposite." One of the parents filled in "Too much praise makes the children 
spoiled, this works with us. This is our culture." One of the other participants tried to explain "In our culture we must tell the child what is wrong, but not in front of others. (...) We take it for granted that the children do what is expected of them, that is why we do not praise them. However, I think it is a good thing to give praise to our children." This discussion amongst the participants is an example of the negotiation of parenting practices that occurred during the course. It illustrates how the parents can express their views and reflect on different ways of upbringing, and that some of the parents changed their view during the course. This illustrates not only how identity is assigned to "culture", but also how aspects of culture and parenting practices are negotiable (Cohen and Kassan 2018; Mollenhauer and Friesen 2014).

Importantly, some of the participants warned against generalisations based on nationality or ethnic origin. One mother was very adamant on this point as she said "I am against talking about groups and making categories, this varies between different families." This statement thus echoes the awareness of differences within cultures (SpencerOatey 2012) and the limitations of cultural stereotypes (Campell 2000; UNESCO 2009, p. 41).

The topics of ignoring and time-out caused expressions of resistance. Examples of behaviour that should be ignored, according to the Incredible Years programme, are "whining, teasing, arguing, swearing and tantrums" (Webster-Stratton 2005, p. 81). Time-out, on the other hand, is to be used for more serious problems like aggression and destructive behaviour (Webster-Stratton 2005, p. 91). "I am against ignoring children under 12, especially when they are crying", one of the parents exclaimed as a response to a role-play. One father touched upon their special context as refugees when he said that it is difficult to be strict towards his children, as he had been arrested and isolated for several days. The course leaders were quick to acknowledge the difficult feelings this could evoke in handling strategies that might remind him of such a terrible experience. As a group, they could also find some useful aspects of ignoring, for instance that the child will learn to know what is right and what is wrong. As a backdrop, they mentioned that the child might be hurt.

These instances of tension and disagreement on parenting practices highlight the complexity of the situation. The dialogic structure of the group opened up for the parents' voices and discussions and reflections internally in the group. The parenting practices did not seem to be imposed on the participants; rather they were encouraged to discuss different views and express their meaning through a dialogic pattern.

The welcoming atmosphere of the meetings supported the dialogue and exchanges in the group. The group leaders often expressed sympathy and support, thus being sensitive to parental perspectives on parenting and child behaviour (Webster-Stratton 2009). The group leaders never pressed the participants to talk about difficult situations and respected instances of reluctance. Rather, the parents were encouraged to talk about positive experiences with their children.

Even though the overall response to the course was positive, one couple stated that they would not recommend the course to other parents. Because they had been parents for many years, they felt that they did not need a parenting course. Their behaviour in meetings occasionally showed a lack of engagement, even though during the interview the mother expressed vexation that none of her fellow participants would admit that 
they had any problems with their children. This attitude offers another perspective on the programme, the status associated with the parental role.

\section{The family as social and cultural capital in a fluctuating context}

Discussions on parenting practices have the potential of bringing social status to the forefront. For instance, the social capital connected to the position as parents may be at stake. This group of parents had left their jobs, their social networks and their extended family behind. It is easy to imagine that preserving their nuclear family and especially their children contained an immense value. "Being called a bad mother is in our culture like swearing" one of the interpreters said during an interview, thus expressing the social value that is connected with family life. This attitude may also explain why the couple who had the longest experience as parents may have felt that their status as successful parents was threatened, whilst the parents who had younger children were more appreciative. In line with this assumption, parents may avoid exposing any challenges in the upbringing of their children, as this will decrease their status as parents.

To support this assumption, the group leaders mentioned during one of the interviews that groups of refugee participants in general rarely, if ever, mentioned that they had any problems in the upbringing of their children, as opposed to groups of Norwegian parent participants, where the parents willingly expressed their struggles with their children. As mentioned, one of the female participants told during the interview that she found it irritating that some of her fellow participants in a previous group would not admit that they occasionally experienced problems with their children. Furthermore, the parents never revealed any kind of disagreement between themselves during the meetings. This finding agrees with Jávo et al. (2000), who state that cultural norms may interfere with communication with professionals. Furthermore, it may be felt inappropriate to share anything about private familial matters as this is considered a breach of cultural norms.

Assigning refugee parents to a parental training programme may thus have deeper implications than those explicitly intended. The implicit message that they have something to learn about child rearing may be felt intrusive. One of the interpreters mentioned that in the community of refugees there was a feeling of inferiority amongst some immigrant parents. When presented to the parenting programme their response could be "Do we have to give up our own ways [of upbringing] to adapt to the new ones?" thus touching upon the issue of assimilation versus integration (Cohen and Kassan 2018; Schneider and Crul 2010; Jávo 2010) and the wish to preserve their own values and practices (UNESCO 2009). In light of Mollenhauer and Friesen's (2014) view on culture and upbringing, the statement expresses the sense of threat towards the transmission of values that is at the core of the relation between parents and children.

Interestingly, even though the parent participants never mentioned challenges with upbringing in the observed group meetings, some of them voiced concerns over their children during the individual interview. Amongst the problems they mentioned were bullying in schools, lack of friends for their children or delayed speaking development. Mentioning these problems in the interviews not only demonstrated their trust in the interpreter (as well as the researcher), but it also confirmed their reluctance to expose problems in the group as a whole. Even though the Incredible Years tries to address this 
issue (Webster-Stratton 2009), such reluctance probably remains a deep-rooted value to many immigrant parents.

Gender roles were not an explicit topic in the course, although equal rights between the genders and mutual respect were addressed during one of the meetings. Implicitly, gender issues came to the forefront during the videotapes (the vignettes) where both mothers and fathers took an active part in the upbringing of their children. The men in the group often explained how they had played with their children or brought them to leisure-time activities, and the men also took part in role-play during the sessions, albeit somewhat reluctantly. It thus seemed that the men also accepted the expectation that they should have an active role in the upbringing of their children.

The value ascribed to the family was especially highlighted when information about the Norwegian Child Welfare Services was on the agenda. This is an element added to this Incredible Years course as there was a great deal of fear and talk of instances where children of immigrant families had been separated from their parents. This discourse in the community of immigrants was partly based on internal communication and rarely corrected by other sources. The participants retold many accounts about conflicts with the Child Welfare Services where children were removed from their families. It was clear that the immigrant population in general was fearful of the Child Welfare Services as information on the reasons for removal of children were mainly based on rumours. The emotional energy in the meeting was prominent, and the precarious situation of immigrant families becomes highlighted when it comes to this issue. The power relations are obviously biased and the parents struggle with their fears of facing a closed and complex system that has the potential of intruding into their families.

Quite a few of the participants were under the misconception that Norwegian Child Welfare Services was a new organisation especially established to overlook immigrant families. It was clarifying when they learnt that the origins for this service dated back to the 1890s and that the present Child Welfare Act originally dates back to 1953, when there were very few immigrants in Norway.

Whilst the social capital of parenthood and successful family life emerged as a poignant theme in the analysis, the issue of cultural capital through education was less prominent. In the initial meeting, the parents were asked to describe their hopes and ambitions for their children. One common ambition was a good education for their children, in line with other research on immigrant families (Raleigh and Kao 2010; Rodríguez-Valls and Torres 2014). A good life in a peaceful society and good health were also mentioned as hopes for their children. One way that the issue of education appeared was when the parents reported about their interaction with schools and kindergartens. They not only praised teachers for their friendly attitude towards their children and themselves, but they also expressed frustration when they experienced problems in communication due to lack of translators. Furthermore, they could not understand the reasons for the provision or lack of provision of mother tongue support in school. Even though this complexity of educational provision for their children was puzzling, the parents were eager to support and encourage their children in their pursuit for an education. 


\section{The interpreters as gatekeepers and cultural "brokers"}

The group leaders considered the interpreters to be their partners in the programme. The interpreter's role was much broader than just rendering the utterances from the group leaders. Previous to the commencement of the course, the interpreters were assigned to a full 3-day course where all the elements of the Incredible Years programme were taught and discussed. Two of the interpreters had also worked as interpreters for previous groups. This gave them a deeper insight into the framework and the rationale behind the Incredible Years programme. Their insight into the programme combined with their language proficiency often resulted in situations where the interpreters themselves solved misunderstandings and could clarify issues during discussions.

The role of the interpreter as gatekeeper was highlighted during one of the interviews. One mother could not understand why her daughter in a second-grade class was not included in the group of immigrant pupils receiving mother tongue instruction in Arabic. The interpreter addressed the researcher and said "I know why, may I explain to her?" He then told her that her daughter was considered having sufficient skills in Norwegian to follow the regular instruction in class, and thus did not qualify for mother tongue instruction. This example of clarification illustrated the interpreter's role as a person who had knowledge to clarify and thus being a mediator in a complex transition phase for a parent.

Kim et al's study (2008) showed that offering the programme in the first language gave additional benefits to the Incredible Years programme. Giving the interpreters a special position where they could demonstrate insight into the programme raised their status amongst the participants and gave them a sense of empowerment. Furthermore, it enhanced the participants' trust in the programme. This particular element of the adaptation of the Incredible Years programme proved to be a very important feature for securing cultural responsiveness in the implementation. The fact that the participants were provided with interpreters that could demonstrate an autonomous role and show insight into the elements of the programme throughout the course, was in itself an appreciation of their special context and proved a responsiveness to them as individuals.

A question that was raised during interviews with the interpreters concerned the issue of mandatory participation. In this case, the enrolment in the Incredible Years course was based solely on the fact that the participants were refugees and newcomers to the Norwegian society. The parents had not voluntarily assigned themselves to the course. This may very well be regarded as exertion of untimely power and also a generalisation based on a prejudice towards people of different ethnic and cultural origins. However, this view was not supported by the interpreters. Three of them pointed to the fact that physical punishment is a normal part of the upbringing in their countries of origin. This was also confirmed by some of the participants during the interviews. The interpreters supported mandatory participation as it was a way of ensuring that all immigrants received the information on laws and regulations regarding upbringing as early as possible. To corroborate this view, many countries in the world lack regulations by law against domestic violence (WorldAtlas n.d.). In this perspective, mandatory participation may be regarded in a more positive light. One of the parents stressed that the course should have started earlier, immediately upon arrival to the municipality, because the content was considered crucial to their role as parents. This would, in her opinion, have 
prevented much anxiety, and the delay in starting up was her only objection against the course.

It should be discussed, however, if mandatory participation of newly arrived immigrants in such an extensive course could be considered unreasonable. Use of the Incredible Years programme as treatment or prevention should particularly be discussed. As none of the participants had expressed any individual need for help in the upbringing of their children, Incredible Years courses should probably refrain from introducing techniques that are developed primarily for children with conduct disorder.

\section{Conclusion}

The UNESCO World Report on cultural diversity (2009) points out the need of encouraging cultural sensitivity in communication and information contents. In this study, the case group consisted of people who were in a vulnerable position. They were newcomers to the country, granted only temporary residence permit, not yet proficient in the language of the country, and enrolled in a mandatory course that highlighted something as private as parenting practises. One finding of this study is that the Incredible Years programme has the potential of an inclusive and culturally responsive communication. The parents expressed that they valued the opportunity to learn about the Norwegian society, and they appreciated a place to discuss issues related to culture and upbringing. In times of uncertainty and transition, the values associated with a successful upbringing may be attributed an even greater value by migrating families, as this can preserve identity and give a sense of agency in their role as parents. This can probably also explain why the parents were reluctant to reveal any problems with their children. The social capital associated with parenthood emerged as an important topic.

The question guiding this research has been how newly arrived refugee parents perceive the cultural responsiveness in the Incredible Years programme. One might ask if assigning refugee families to a programme that so closely involves family life is too intrusive. This investigation found that although the programme builds on western concepts of child rearing and upbringing, the dialogic structure of the programme and the use of interpreters ensured a certain degree of responsiveness. One specific feature of this implementation was the empowered role of the interpreters, who were considered co-workers with the group leaders and were given a more meaningful role in the programme than just translating utterances between the participants and the leaders. The interpreters' status assisted the participants in negotiating their own position in a new context, and provided the participants with an arena to maintain their status and adapt their identity as parents in a new context.

The research also showed that taking part in a multilingual and multicultural group gave the participants an opportunity to interact with each other in ways that supported their building networks in the new community, thus adding to their social capital. They appreciated learning about similarities and differences between cultures, which is a way of avoiding stereotypes. Participating in a diverse group allowed negotiations of parenting practices in a supportive way, and should also be considered an outcome of this implementation of the Incredible Years programme. 


\section{Acknowledgements}

The author would like to acknowledge the group of participants, the interpreters and the group leaders who allowed her to sit in regularly at meetings for 1 year, who volunteered for individual interviews and answered questions when clarification was needed. Without their contributions, this research would not have been possible.

\section{Authors' contributions}

The author read and approved the final manuscript.

Funding

The research article is funded by Inland Norway University of Applied Sciences. Field observation was funded by the municipality.

\section{Availability of data and materials}

Data sharing is not applicable to this article as no datasets were generated or analysed during the current study.

\section{Competing interests}

The author declares no competing interests.

Received: 7 July 2019 Accepted: 7 May 2020

Published online: 13 May 2020

\section{References}

Barth, F. (1998). Ethnic groups and boundaries: The social organization of culture difference. Prospect Heights: Waveland Press.

Bourdieu, P. (1997). The forms of capital. In A. Halsey, H. Lauder, P. Brown, \& A. Wells (Eds.), Education, culture, economy, and society (pp. 46-58). Oxford: Oxford University Press.

Bronfenbrenner, U. (1986). Ecology of the family as a context for human development: Research perspectives. Developmental Psychology, 22(6), 723-742.

Calgary Immigrant Women's Association CIWA. (2019). Cross cultural parenting program (CCPP) resource manual. https:// www.ciwa-online.com/resources/publications.html.

Campbell, A. (2000). Cultural identity as a social construct. Intercultural Education, 11(1), 31-39. https://doi. org/10.1080/14675980050005370

Central Manchester University Hospitals, NHS Foundation Trust. (2015). The children and parents service (CAPS). https://mft. nhs.uk/rmch/the-children-and-parents-service-caps/.

Cohen, J. A., \& Kassan, A. (2018). Being in-between: A model of cultural identity negotiation for emerging adult immigrants. Journal of Counseling Psychology, 65(2), 133-154. https://doi.org/10.1037/cou0000265.

Creswell, J. W. (2014). Research design: Qualitative, quantitative, and mixed methods approaches (4th ed.). Los Angeles: Sage.

Directorate of Integration and Diversity. (2018). The introduction programme. Retrieved November 20, 2018 from https:// www.imdi.no/en/the-introduction-programme/the-introduction-programme/.

Drugli, M. B., Larsson, B., \& Clifford, G. (2007). Changes in social competence in young children treated because of conduct problems as viewed by multiple informants. European Child and Adolescent Psychiatry, 16(6), 370-378.

European Commission (2018). Common European Asylum System. Retrieved November 14, 2018 from https://ec.europ a.eu/home-affairs/what-we-do/policies/asylum en.

Fossum, S., Handegård, B., \& Drugli, M. B. (2017). The incredible years teacher classroom management program in kindergartens: Effects of a universal preventive effort. Journal of Child and Family Studies, 26(8), 2215-2223. https://doi. org/10.1007/s10826-017-0727-3.

Furlong, M., \& McGilloway, S. (2011). The Incredible Years Parenting Program in Ireland: A qualitative analysis of the experience of disadvantaged parents. Clinical Child Psychology and Psychiatry, 17(4), 616-630. https://doi. org/10.1177/1359104511426406

Fyhn, O. (2017). Dressur eller humanisme: En gjennomgang av «De utrolige årene»- et program for forebygging og behandling av atferdsvansker hos barn. [Dressage or humanism: A review of "The Incredible Years" - a programme for prevention and treatment of behavioural problems in children]. Scandinavian Psychologist, (4), e5. https://doi. org/10.15714/scandpsychol.4.e5.

Geertz, C. (1973). The interpretation of cultures. New York, NY: Basic Books.

Haines, S. J., Summers, J. A., Palmer, S. B., Chu, S. Y., \& Stroup-Rentier, V. L. (2017). Immigrant families' perceptions of fostering their preschoolers' foundational skills for self-determination. Inclusion, 5(4), 293-305. https://doi. org/10.1352/2326-6988-5.4.293.

Harouna, (2018). Early childcare and development in Central African refugee families in Cameroon Mbere villages. In H. B. Ebrahim, A. Okwany, \& O. Barry (Eds.), Early childhood care and education at the margins: African perspectives on birth to three (pp. 31-45). New York: Routledge.

Incredible Years. (n.d.a). Incredible Years parent, teacher and child programs fact sheet. Retrieved December 3, 2018 from http://www.incredibleyears.com/about/.

Jávo, C. (2010). Kulturens betydning for oppdragelse og atferdsproblemer: Transkulturell forståelse, veiledning og behandling. [The effect of culture for upbringing and disruptive behaviour: Transcultural perceptions, counselling and treatment]. Oslo: Universitetsforlaget.

Jávo, C., Heyerdahl, S., \& Rønning, J. A. (2000). Parent reports of child behavior problems in young Sami children: A crosscultural comparison. European Child and Adolescent Psychiatry, 9(3), 202-211.

Kim, E., Cain, K. C., \& Webster-Stratton, C. (2008). The preliminary effect of a parenting program for Korean American mothers: A randomized controlled experimental study. International Journal of Nursing Studies, 45(9), 1261-1273. 
Kirkhaug, B., Drugli, M. B., Klöckner, C. A., \& Mørch, W.-T. (2013). Association between parental involvement in school and child conduct, social and internalizing problems: Teacher report. Educational Research and Evaluation: An International Journal on Theory and Practice, 19(4), 346. https://doi.org/10.1080/13803611.2013.771893.

Leijten, P., Raaijmakers, M. A. J., de Castro, B. O., van den Ban, E., \& Matthys, W. (2017). Effectiveness of the Incredible Years parenting program for families with socioeconomically disadvantaged and ethnic minority backgrounds. Journal of Clinical Child \& Adolescent Psychology, 46(1), 59-73. https://doi.org/10.1080/15374416.2015.1038823.

McGrath, P. J., \& Elgar, F. J. (2015). Effects of socio-economic status on behavioral problems. In J. D. Wright (Ed.), International Encyclopedia of the Social \& Behavioral Sciences (2nd ed., pp. 477-482). Amsterdam: Elsevier.

Meissner, F., \& Vertovec, S. (2015). Comparing super-diversity. Ethnic and Racial Studies, 38(4), 541-555. https://doi. org/10.1080/01419870.2015.980295.

Menting, A. T., de Castro, B. O., \& Matthys, W. (2013). Effectiveness of the Incredible Years parent training to modify disruptive and prosocial child behavior: A meta-analytic review. Clinical Psychology Review, 33(8), 901-913. https://doi. org/10.1016/..cpr.2013.07.006.

Migration Data Portal. (2017). Total number of international migrants. Retrieved July 2, 2019 from https://migrationd ataportal.org/?i=stock_abs_\&t=2017.

Mollenhauer, K., \& Friesen, N. (2014). Forgotten connections: On culture and upbringing (Theorizing education series). London: Routledge.

Norwegian Directorate of Immigration (UDI). (n.d.a). Resettlement refugees (quota refugees). Retrieved July 2, 2019 from https://www.udi.no/en/word-definitions/resettlement-refugees/.

Norwegian Directorate of Immigration (UDI). (n.d.b). Asylum seekers lodged in Norway by citizenship, sex and age (2015) Retrieved November 29, 2018 from https://www.udi.no/en/statistics-and-analysis/statistics/asylum-applicationslodged-in-norway-by-citizenship-sex-and-age/.

OECD. (2017). A portrait of family migration in OECD countries. International migration outlook 2017. Retrieved July 2, 2019 from https://www.oecd.org/els/mig/IMO-2017-chap3.pdf.

Østrem, S. (2016). Program til hinder for demokratisk deltakelse. [Programme obstructing democratic participation.] Dansk pædagogisk tidsskrift, (3). Retrieved July 2, 2019 from http://www.dpt.dk/wp-content/uploads/2010/06/ S\%C3\%98-fin.pdf.

Raleigh, E., \& Kao, G. (2010). Do immigrant minority parents have more consistent college aspirations for their children? Social Science Quarterly, 91(4), 1083-1102.

Reinke, W. M., Stormond, M., Webster-Stratton, C., Newcomer, L. L., \& Herman, K. C. (2012). The Incredible Years teacher classroom management program: Using coaching to support generalization to real-world classroom settings. Psychology in the Schools, 49(5), 416-428.

Rodríguez-Valls, F., \& Torres, C. (2014). Partnerships \& networks in migrant education: Empowering migrant families to support their children's success. Multicultural Education, 21(3/4), 34-38.

Schneider, J., \& Crul, M. (2010). New insights into assimilation and integration theory: Introduction to the special issue. Ethnic and Racial Studies, 33(7), 1143-1148. https://doi.org/10.1080/01419871003777809.

Seabra-Santos, M. J., Gaspar, M. F., Azevedo, A. F., Homem, T. C., Guerra, J., Martins, V., et al. (2016). Incredible Years parent training: What changes, for whom, how, for how long? Journal of Applied Developmental Psychology, 44(2016), 93-104. https://doi.org/10.1016/j.appdev.2016.04.004.

Skar, A.-M. S., Bjørnstad, S., \& Davidsen, H. (2014). ICDP-foreldreveiledning i Oslo Voksenopplæring som en del av Introduksjonsprogrammet for innvandrere og flyktninger. Et pilotprosjekt. [ICDP parenting counselling in Oslo Adult Education as a part of the introductory programme for immigrants and refugees. A pilot project]. Retrieved June 20, 2019 from https://www. icdp.no/wp-content/uploads/2019/04/2014-06-20-Rapport_ICDP_Introduksjonsprogrammet.pdf.

Spencer-Oatey, H. (2008). Culturally speaking: Culture, communication and politeness theory (2nd ed.). London: Continuum.

Spencer-Oatey, H. (2012). What is culture? A compilation of quotations. GlobalPAD core concepts. Available at GlobalPAD Open House, Retrieved June 20, 2019 from http://www.warwick.ac.uk/globalpadintercultural.

Statistics Norway. (2019). Fakta om innvandring. [Facts about immigration]. Retrieved June 20, 2019 from https://www. ssb.no/innvandring-og-innvandrere/faktaside/innvandring.

UNESCO. (2009). World report. Investing in cultural diversity and intercultural dialogue. Retrieved November 26, 2018 from http://www.un.org/en/events/culturaldiversityday/pdf/Investing_in_cultural_diversity.pdf.

UNHCR. (n.d.). The 1951 Refugee Convention. Retrieved November 26, 2018 from https://www.unhcr.org/1951-refug ee-convention.html.

Webster-Stratton, C. (2005). The Incredible Years: A trouble-shooting guide for parents of children aged 2-8. Seattle: Incredible Years.

Webster-Stratton, C. (2009). Affirming diversity: Multi-cultural collaboration to deliver The Incredible Years parent programs. International Journal of Child Health and Human Development, 2(1), 17-32.

Webster-Stratton, C., \& Herman, K. C. (2009). Disseminating Incredible Years Series early-intervention programs: Integrating and sustaining services between school and home. Psychology in the Schools, 47(1), 36-54. https://doi. org/10.1002/pits.20450

WorldAtlas. (n.d.). Nations without domestic violence regulation. Retrieved July 2, 2019 from https://www.worldatlas .com/articles/nations-without-domestic-violence-regulation.html.

Yin, R. (2014). Case study research: Design and methods (5th ed.). Thousand Oaks, CA: Sage.

\section{Publisher's Note}

Springer Nature remains neutral with regard to jurisdictional claims in published maps and institutional affiliations. 